\title{
Assessing the Influence of Living and Working Conditions on Alcohol Consumption in Migrant Farmworkers in Mexico
}

\author{
Luis A. Valdez ${ }^{1}$, Melanie L. Bell ${ }^{2}$, and David O. Garcia ${ }^{1}$ \\ ${ }^{1}$ University of Arizona Mel and Enid Zuckerman College of Public Health \\ Department of Health Promotion Sciences \\ ${ }^{2}$ University of Arizona Mel and Enid Zuckerman College of Public Health \\ Department of Biostatistics and Epidemiology
}

\begin{abstract}
Background and Purpose: Inadequate working and living conditions are associated with alcohol consumption in farmworkers in the U.S. However, the influence of these factors on alcohol consumption patterns in migrant farmworkers in Mexico remains unclear. The purpose of this analysis was to assess the influence of housing and working conditions on alcohol use in migrant farmworkers in Mexico. Methods: We used logistic and ordinal logistic regression to examine the association of living and working conditions on alcohol consumption and frequency in 3,132 farmworkers in Mexico with data from a Mexican national farmworker's survey. Results: Living in inadequately built homes $(\mathrm{OR}=0.84$; 95\% $\mathrm{CI}=0.72,0.98 ; \mathrm{p}<0.05)$ and limited access to luxury items $(\mathrm{OR}=0.69 ; 95 \% \mathrm{CI}=0.52,0.94 ; \mathrm{p}<0.01)$, were associated with a decreased likelihood to consume alcohol compared to living in better conditions. In contrast, living in employer provided housing $(\mathrm{OR}=1.79 ; 95 \% \mathrm{CI}=1.40,2.31 ; \mathrm{p}<0.0001)$ and experiencing hazards related to safety $(\mathrm{OR}=1.69 ; 95 \% \mathrm{CI}=1.35,2.12 ; \mathrm{p}<0.0001)$, work organization $(\mathrm{OR}=1.29 ; \mathrm{CI}=1.03,1.63 ; \mathrm{p}<0.05)$, and ergonomics $(\mathrm{OR}=2.04 ; \mathrm{CI}=1.18,3.52 ; \mathrm{p}<0.05)$ increased the likelihood of consuming alcohol. Conclusion: Living and working conditions of farmworkers may affect alcohol consumption. However, these findings require replication and specific mechanisms, which may influence these results warrants investigation.
\end{abstract}

(C) 2016 Californian Journal of Health Promotion. All rights reserved. Keywords: Migrant, Farmworkers, Alcohol, Occupational Health, Mexico, Housing

\section{Introduction}

The expanding agribusiness in northern Mexico has increased the demand for temporary migrant farmworkers from the south of the country. According to estimates, in 2011, there were two million farmworkers in Mexico, of which $21.3 \%$ needed to migrate to find work (SEDESOL, 2011). The demand called for the movement of over 420,000 Mexican farmworkers, a number that continues to expand along with the growing market (SEDESOL, 2011). Due to this increased demand, farmworkers are becoming exposed to increased occupational risks and hazards (Palacios et al., 2000). These risks and hazards may be compounded by inadequate housing conditions that can also be harmful to worker health.
Mexican farmworkers often live in overcrowded conditions that lack the most basic services (Palacios-Nava \& Moreno-Tetlacuilo, 2004). Housing conditions range anywhere from sleeping in makeshift shelters in the fields to more common arrangements that consist of farm owned labor camps located near the rural farms in which they work (Palacios et al., 2000; Palacios-Nava \& Moreno-Tetlacuilo, 2004). Rural farm provided living quarters often consist of dormitory-style rooms with $10-90$ beds, and limited to no access to potable water, bathrooms, washrooms, bedding, and electricity (PalaciosNava \& Moreno-Tetlacuilo, 2004). Inadequate conditions in labor camps, including poor sanitation, crowding, and lack of recreational outlets have been associated with alcohol consumption in farmworkers in the U.S. (McDermott \& Lee, 1990). It has also been 
demonstrated that U.S. farmworkers are more likely to consume alcohol and are at higher risk of alcohol dependence than non-farmworkers (Arcury et al., 2016). However, potential causal pathways for this association remain unclear.

Material deprivation, crowded housing, home and neighborhood disrepair, and lack of basic services have all been linked to higher rates of consumption and abuse of alcohol in general U.S. non-farmworker samples (Hill \& Angel, 2005; Pollack, Cubbin, Ahn, \& Winkleby, 2005). Studies also have shown that residents of disadvantaged living spaces drink more often and more heavily than their more affluent counterparts (Hill \& Angel, 2005; Makela, 1999; Pollack et al., 2005). Hill and Angel (2005) posited that the stress of living in spaces that are characterized by deprivation can be psychologically distressing and can lead people to consume alcohol as a means of palliative escape, which can prove harmful to health. The consumption of alcohol has been established as a partial cause of a wide variety of health conditions, including neuropsychiatric disorders, certain cancers, cardiovascular diseases, and infectious diseases (WHO, 2014). Excessive alcohol consumption is linked to increased risk of unintentional and work-related injuries (WHO, 2014), and given the occupational hazards already faced by farmworkers (Palacios et al., 2000), risk of occupational injury is exacerbated for those who drink (Campillo, Romero, Saldivar, \& Ramos, 1998; Wang et al., 2010; Webb et al., 1994; Zhou \& Roseman, 1994). While the literature is sparse, evidence indicates that poor working and living conditions as well as material deprivation are associated with increased alcohol consumption. However, these associations exist primarily in U.S. samples and little is known about similar associations in farmworkers in Mexico.

As a result of the housing, working, and health issues seen in the agricultural working community in Mexico, the Encuesta Nacional de Jornaleros (ENJO) (National Agricultural Worker's Survey) was formulated to collect data that would increase the efficiency of strategic planning toward building better social welfare programs for migrant farmworkers (SEDESOL,
2009). The objective of the current analysis was to use data gathered as part of the ENJO to assess whether housing and working conditions are influential factors for alcohol use in farmworkers in Mexico and explore a potential pathway of material deprivation to alcohol consumption. We hypothesized that farmworkers who live and work in inadequate conditions (as defined below) were more likely to consume alcohol than their counterparts that live and work in better conditions. As an exploratory assessment, we also hypothesized that farmworkers who live and work in inadequate conditions were more likely to consume alcohol with greater frequency as compared to their counterparts. Findings from this work have the potential to add to the poorly understood etiology of alcohol consumption patterns in farmworker populations which have been shown to be disproportionately high compared to non-farmworkers (Arcury et al., 2016). A better understanding of the factors that influence alcohol consumption in this population can serve to inform targeted intervention efforts that diminish the detrimental physical, behavioral, and social impact of maladaptive alcohol consumption patterns in this vulnerable population.

\section{Methods}

\section{Data Source and Study Participants}

Data for this study were from the ENJO conducted in collaboration by Mexico's national social welfare agency (SEDESOL) and La Universidad Autonoma Chapingo (UACh). Investigators from both SEDESOL and UACh used the ENJO (survey) to collect data on 3,152 migrant farmworkers between May 2008 and January 2009. Investigators completed surveys with farmworkers living and working in 689 different municipalities in Mexico and collected an average of 4 farmworker questionnaires from each municipality; although the range extended from 1 to 114 and depended on the population density of individual municipalities. SEDESOL and UACh investigators utilized employee lists that were required to be kept by agricultural employers to identify and randomly select eligible questionnaire participants. The questionnaires were conducted face-to-face and occurred at the farmworker's place of 
employment or in their home when necessary. Because of the nature of the sensitive information collected, the interview was completed when the worker was alone and without work-related responsibilities to fulfill. In order to obtain a sample that was as generalizable as possible, investigators took into account a variety of agricultural labor cycle related factors including: estimates of national agricultural workforce, national crop density for each of the 12 highest farmed crops in Mexico, and labor and workforce density according to agricultural cycle for each of the 12 highest farmed crops. Researchers aimed to sample a representative ratio of workers from each of the 12 most popular crops, which represent $80 \%$ of the national yield (the crop variability remaining $20 \%$ was too diverse and thus difficult to measure) during harvest season, a time in the agricultural cycle where workforce and labor is the densest. This strategy ensured adequately representative sampling in the first data collection effort of its kind with farmworkers in Mexico. Further details regarding ENJO study design and data collection are available elsewhere (SEDESOL, 2009). ENJO data are de-identified and publically available. Secondary analysis of these data therefore does not constitute human subjects research as defined by federal regulations and does not require institutional review board assessment.

\section{Outcome Measures}

All measures were self-reported. Alcohol consumption and frequency were reported as binary and ordinal variables, with the latter reported as never, not often, once a week, or daily. Working conditions included binary suffering of work-related injuries (agrochemical intoxication, dehydration, heat stroke, and burns) and exposure to work-related hazards, which were compartmentalized into 5 binary variables; exposure to safety hazards (exposure to working from heights, working with fire), exposure to physical hazards (constant loud noise, temperature extremes), exposure to ergonomic hazards (frequent heavy lifting, repetitive motion, long standing or crouching), exposure to chemical hazards (agrochemicals, dust) and exposure to work organization hazards (workload demands, wage or workload deception, verbal abuse, physical abuse, and sexual abuse).

Housing conditions were discerned from questions asking participants what materials composed the majority of their roof, walls, and flooring. Available responses were cement, adobe, brick, wood, corrugated steel, palm, bamboo, cardboard, and dirt/sand. The three house domains (roof, walls, flooring) were considered separately and were coded as binary variables into adequate and inadequate. Adequately constructed walls and roofing were composed of cement, adobe, brick, wood, or corrugated steel, while inadequate walls or roofing consisted of palm, reed, or cardboard. An adequate floor was composed of cement, adobe, brick, or some form of decorative tile, or wood while an inadequate floor consisted of dirt or sand. To facilitate the analysis and standardize our methods, a housing adequacy score was developed that included an adequacy scale of $0-3$. A score of 0 meant that the materials in all three domains were adequate, a score of 1 meant that only one material of the three domains was inadequate, 2 meant that two materials were inadequate, while a score of 3 would imply that all materials composing the roof, walls, and flooring were inadequate. Other binary variables included whether or not participants lived in employee provided housing; access to all basic services (electricity, sewage, water); and access to any luxury items (as defined by ENJO: blender, refrigerator, radio, television, gas stove, or washing machine).

Demographic variables including age, sex, race/ethnicity, education, and marital status were included as well. Race/ethnicity was discerned by the participant's ability to speak an indigenous language ("yes" or "no"), as race/ethnicity was not directly measured as part of the ENJO questionnaire. Education was categorized into less than primary; completion of primary; completion of secondary; and preparatory (equivalent to high school) or college. Finally, marital status was categorized into married/union, single, separated/widowed/ divorced. 


\section{Statistical Analyses}

We used logistic regression to assess the association between housing and working conditions and our primary outcome of alcohol consumption. A series of 3 models were fit, each with an increased number of relevant variables. Model 1 included only housing condition variables. Model 2 included all housing and working conditions. Model 3 included housing and working conditions adjusted for all relevant sociodemographic factors. Participants with missing observations in any of the variables used for this analysis were removed $(n=20)$. As an exploratory analysis, we used ordinal logistic regression to analyze alcohol frequency following the same modeling scheme as in our logistic regression models. All assumptions of logistic and ordinal logistic regression were assessed. All analyses were completed using STATA 13 statistical computing software package (StataCorp, 2013).

\section{Results}

Table 1 contains demographic characteristics by drinking status for the 3,132 participants in the sample used for this analysis. Approximately $13 \%$ of participants reported any alcohol consumption. The mean ages of drinkers and non-drinkers were 37 and 35 years, respectively. The large majority (97.3\%) of drinkers were male, and $68.3 \%$ were married or in some kind of union. Over half $(57.1 \%)$ of drinkers reported not finishing primary school and only $3.2 \%$ finished preparatory school (equivalent to high school). Nearly half $(47.4 \%)$ of drinkers reported living in a space where at least one housing domain was inadequate and $3.5 \%$ reported living in a space where all materials were inadequate. Nearly $12.2 \%$ of drinkers reported access to all basic services, while $10 \%$ of non-drinkers reported access to all basic services. Access to any luxury items was reported by $19.5 \%$ of all drinkers and $14.4 \%$ of non-drinkers. Nearly all participants (91.2\%) had been exposed to ergonomic hazards, over $85 \%$ of participants had been exposed to some physical hazard, $68.1 \%$ had been exposed to dust/chemical hazards, only $34.9 \%$ of participants were exposed to safety hazards, and $35.8 \%$ of participants were exposed to work organization hazards. Injuries were suffered by a total $53.1 \%$ of drinkers and $39.3 \%$ of nondrinkers.

\section{Table 1.}

Descriptive Statistics by Drinking Status for Sociodemographics, Housing, and Working Conditions for Participants of the 20082009 ENJO $(n=3,132)$

\begin{tabular}{|c|c|c|c|c|c|c|}
\hline \multirow{3}{*}{\begin{tabular}{cc} 
& $\mathrm{B}$ \\
\cline { 2 - 2 } & $\mathrm{D}$ \\
& {$[\mathrm{n}$} \\
Mean Age (SD) & 37
\end{tabular}} & \multicolumn{3}{|c|}{$\begin{array}{l}\text { By Drinking Status } \\
\text { Drinkers Non-Drinkers } \\
{[\mathrm{n}=401][\mathrm{n}=2,731]}\end{array}$} & \multicolumn{3}{|c|}{$\begin{array}{l}\text { Full Sample } \\
\text { Full Sample } \\
{[\mathrm{n}=3,132]}\end{array}$} \\
\hline & \multicolumn{2}{|c|}{13.7} & 35 & 4.1 & \multicolumn{2}{|c|}{14.1} \\
\hline & $\mathrm{n}$ & $\%$ & $\mathrm{n}$ & $\%$ & $\mathrm{n}$ & $\%$ \\
\hline Male Sex & 390 & 97.3 & 2,155 & 78.9 & 2,545 & 81.3 \\
\hline Indigenous Race & 71 & 17.7 & 623 & 22.8 & 694 & 22.2 \\
\hline \multicolumn{7}{|l|}{ Marital Status } \\
\hline Married/Union & 274 & 68.3 & 1,891 & 69.2 & 2,165 & 69.1 \\
\hline Single & 101 & 25.2 & 692 & 25.3 & 739 & 25.3 \\
\hline $\begin{array}{l}\text { Separated/Widow } \\
\text { or Divorced }\end{array}$ & 26 & 6.5 & 148 & 5.4 & 174 & 5.6 \\
\hline \multicolumn{7}{|l|}{ Education } \\
\hline$<$ Prin & 229 & 57.1 & 1,470 & 53.8 & 1,699 & 54.3 \\
\hline Prim & 94 & 23.4 & 660 & 24.2 & 754 & 24.1 \\
\hline Secol & 65 & 16.2 & 483 & 17.7 & 548 & 17.5 \\
\hline Prep & 13 & 3.2 & 118 & 4.3 & 131 & 4.2 \\
\hline \multicolumn{7}{|c|}{ Housing Conditions* } \\
\hline House Score $=0$ & 143 & 35.7 & 826 & 30.3 & 969 & 30.9 \\
\hline Hous & 190 & 47.4 & 1,355 & 49.6 & 1,545 & 49.3 \\
\hline Hous & 54 & 13.5 & 472 & 17.3 & 526 & 16.8 \\
\hline Hous & 14 & 3.5 & 78 & 2.9 & 92 & 2.9 \\
\hline $\begin{array}{l}\text { Employer- } \\
\text { Provided }\end{array}$ & 262 & 65.3 & 2,031 & 74.4 & 2,293 & 73.2 \\
\hline $\begin{array}{l}\text { Non-Employer- } \\
\text { Provided }\end{array}$ & 139 & 34.7 & 700 & 25.6 & 839 & 26.8 \\
\hline $\begin{array}{l}\text { Has all basic } \\
\text { services }\end{array}$ & 49 & 12.2 & 273 & 10.0 & 322 & 10.3 \\
\hline Has Luxury Items & 78 & 19.5 & 394 & 14.4 & 472 & 15.1 \\
\hline \multicolumn{7}{|l|}{ Working Conditions } \\
\hline $\begin{array}{l}\text { Dust/Chemical } \\
\text { Hazards }\end{array}$ & 309 & 77.1 & 1842 & 66.8 & 2,133 & 68.1 \\
\hline Safety & 211 & 52.6 & 881 & 32.3 & 1,092 & 34.9 \\
\hline $\begin{array}{l}\text { Organization } \\
\text { Hazards }\end{array}$ & 190 & 47.4 & 930 & 34.1 & 1,120 & 35.8 \\
\hline $\begin{array}{l}\text { Ergonomic } \\
\text { Hazards }\end{array}$ & 386 & 96.3 & 2,471 & 90.5 & 2,857 & 91.2 \\
\hline Physical I & 366 & 91.3 & 2,296 & 94.1 & 2,662 & 85.9 \\
\hline Suffered Injuries & 213 & 53.1 & 1073 & 39.3 & 1286 & 41.1 \\
\hline
\end{tabular}

* Housing adequacy score of 0 meant that the materials in all three domains (flooring, roofing, and walls) were adequate, a score of 1 meant that only one material of the three domains was inadequate, 2 meant that two materials were inadequate, while a score of 3 would imply that materials in all domains were inadequate. 
Table 2 contains the results of the multivariable logistic regression model that we used to explore relationships between housing and working conditions and any alcohol consumption. The model includes all housing and working conditions adjusted for age, sex, race/ethnicity, marital status and educational attainment. Our findings suggest that farmworkers that lived in employer provided housing had $76 \%$ higher odds of consuming alcohol $(\mathrm{OR}=1.76 ; 95 \%$ $\mathrm{CI}=1.37,2.271 ; \mathrm{p}<0.0001)$. In contrast, for each unit increase in housing inadequacy, the odds of alcohol consumption decreased by $16 \%(\mathrm{OR}=$ $0.84 ; 95 \% \mathrm{CI}=0.72,0.98 ; \mathrm{p}<0.05)$ and workers with no access to any luxury items had $30 \%$ lower odds of reporting alcohol consumption, yielding $\mathrm{OR}=0.70(95 \% \mathrm{CI}=0.52,0.94 ; \mathrm{p}<0.01)$. Workers who experienced safety-related hazards had a $69 \%$ higher odds of consuming alcohol $(\mathrm{OR}=1.69 ; 95 \% \mathrm{CI}=1.35,2.12 ; \mathrm{p}<0.0001)$. Those who experienced work organization hazards and ergonomic hazards had a $29 \%(\mathrm{OR}=$ 1.29 ; $\mathrm{CI}=1.03,1.63 ; \mathrm{p}<0.05)$, and a $104 \%(\mathrm{OR}=$ 2.04; $\mathrm{CI}=1.18,3.52 ; \mathrm{p}<0.05)$, greater odds of consuming alcohol respectively. Finally, workers who suffered work related injuries had a $54 \%(\mathrm{OR}=1.54 ; \mathrm{CI}=1.23,1.93 ; \mathrm{p}<0.01)$ higher odds of consuming alcohol. All assumptions of logistic regression were met and Hosmer Lemeshow goodness of fit statistics yielded insignificant results $(p=0.70)$ indicating that the model was appropriately fit. An ROC curve assessment of our model yielded a $\mathrm{C}$-index of 0.70 . No substantive differences were observed in the associations between our exposure and outcome variables throughout models 1-3, therefore we only present results for our final model in Table 2.

Table 3 shows the results of an exploratory multivariable ordinal logistic regression model that assessed the relationship between housing and working conditions and frequency of alcohol consumption (never, not often, once a week, or daily). Our ordinal logistic regression model followed the same modeling scheme as logistic regression for any alcohol consumption and included all living and working conditions adjusted for age, sex, race/ethnicity, marital status and educational attainment. Findings indicate that as housing adequacy worsened, the

Table 2.

Binary Logistic Regression of Working and Housing Conditions on Any Alcohol Consumption in Mexican Farmworkers $(\mathrm{n}=3,132)$.

Housing Conditions

OR $\quad 95 \% \mathrm{CI} \quad$ AOR $\quad 95 \% \mathrm{CI}$

Housing Score $\quad 0.85 * \quad 0.73,0.99 \quad 0.84 * \quad 0.72,0.98$

Employer-Provided 1.56*** $1.23,1.98$ 1.76*** $1.37,2.27$

Housing

No Access to Basic $0.83 \quad 0.59,1.18 \quad 0.83 \quad 0.58,1.18$

Services

No Access to $\quad 0.69 * * \quad 0.52,0.93 \quad 0.70 * * \quad 0.52,0.94$

"Luxury" Items

Working

Conditions

Dust/Chemical $\quad 1.17 \quad 0.89,1.53 \quad 1.11 \quad 0.85,1.46$

Hazards

Safety Hazards $\quad 1.94 * * * 1.56,2.42 \quad 1.69 * * * 1.35,2.12$

$\begin{array}{lllll}\text { Organization } & 1.28 * & 1.02,1.60 & 1.29 * & 1.03,1.63\end{array}$

Hazards

Ergonomic Hazards 1.93* $1.12,3.33$ 2.04* $1.18,3.52$

Physical Hazards $\quad 1.37 \quad 0.92,2.03 \quad 1.39 \quad 0.94,2.08$

Work Related $\quad 1.36 * * \quad 1.09,1.70 \quad 1.54 * * * 1.23,1.93$

Injuries

Notes. Reference categories were: adequacy score of 0

(flooring, roof, and walls were all adequately built), non-

employee provided housing, access to all basic services, any access to luxury items, no exposure to work related hazards, no exposure to specified work-related hazards. Final model was adjusted for: age, sex, race/ethnicity, education, and marital status.

$* \mathrm{p}<0.05, * * \mathrm{p}<0.01, * * * \mathrm{p}<0.0001$

-C-index for final model $=0.70$

odds of drinking with more frequency decreased by $15 \% \quad(\mathrm{OR}=0.85 ; 95 \% \quad \mathrm{CI}=0.73 \quad 0.99$; $\mathrm{p}<0.05)$. Workers that lived in employer provided housing had $72 \%$ increased odds of consuming alcohol with greater frequency $(\mathrm{OR}=1.72 ; \quad 95 \% \quad \mathrm{CI}=1.34 \quad 2.21 ; \mathrm{p}<0.0001)$. Workers who experienced safety-related hazards had a 74\% higher odds of consuming alcohol with greater frequency $(\mathrm{OR}=1.74 ; 95 \% \mathrm{CI}=$ $1.38,2.18 ; \mathrm{p}<0.0001)$. Those who experienced work organization hazards and ergonomic hazards had a $32 \%(\mathrm{OR}=1.32 ; \mathrm{CI}=1.04,1.65$; $\mathrm{p}<0.05)$, and a 99\% $(\mathrm{OR}=1.99 ; \mathrm{CI}=1.15,3.43$; $\mathrm{p}<0.05)$ greater odds of consuming alcohol, respectively. Suffering a work related injury yielded an $\mathrm{OR}=1.55 \quad(95 \% \quad \mathrm{CI}=1.24, \quad 1.94$; $\mathrm{p}<0.0001)$. No significant differences were observed in the associations between our exposure and outcome variables throughout 
models $1-3$, therefore we only present results for our final model in Table 3.

Table 3.

Ordinal Logistic Regression of Working and Housing Conditions on Frequency of Alcohol Consumption (Never, Not Often, Once a Week, 2-3 Times a Week, and daily) in Mexican farmworkers $(\mathrm{n}=3,132)$

Housing Conditions

\begin{tabular}{|c|c|c|c|c|}
\hline & OR & $95 \% \mathrm{CI}$ & AOR & $95 \% \mathrm{CI}$ \\
\hline Housing Score & $0.85^{*}$ & $0.73,0.98$ & $0.84 *$ & $0.73,0.99$ \\
\hline $\begin{array}{l}\text { Employer-Providec } \\
\text { Housing }\end{array}$ & $11.53 * * *$ & $1.22,1.94$ & $1.72 * * *$ & $1.34,2.21$ \\
\hline $\begin{array}{l}\text { No Access to Basi } \\
\text { Services }\end{array}$ & 0.84 & $0.52,0.92$ & 0.85 & $0.59,1.20$ \\
\hline $\begin{array}{l}\text { No Access to } \\
\text { "Luxury" Items } \\
\text { Working } \\
\text { Conditions }\end{array}$ & $0.69 * *$ & $0.52,0.92$ & $0.69 * *$ & $0.51,0.92$ \\
\hline $\begin{array}{l}\text { Dust/Chemical } \\
\text { Hazards }\end{array}$ & 1.17 & $0.89,1.52$ & 1.11 & $0.85,1.46$ \\
\hline Safety Hazards & $1.99 * * *$ & $1.60,2.48$ & $1.74 * * *$ & $1.38,2.18$ \\
\hline $\begin{array}{l}\text { Organization } \\
\text { Hazards }\end{array}$ & $1.29 *$ & $1.03,1.61$ & $1.32 *$ & $1.04,1.65$ \\
\hline Ergonomic Hazard & s $1.90 *$ & $1.10,3.27$ & $1.99 *$ & $1.15,3.43$ \\
\hline Physical Hazards & 1.38 & $0.93,2.04$ & 1.41 & $0.95,2.09$ \\
\hline $\begin{array}{l}\text { Work Related } \\
\text { Injuries }\end{array}$ & $1.58 * *$ & $1.27,1.97$ & $1.55 * * *$ & $1.24,1.94$ \\
\hline
\end{tabular}

\section{Discussion}

The objective of the current analysis was to use data gathered as part of the ENJO to assess whether housing and working conditions were influential factors of alcohol use for farmworkers in Mexico. Consistent with our hypothesis, our findings demonstrated that workers who lived in employer provided housing were more likely to consume alcohol and with more frequency than their counterparts who lived in better conditions. Further, workers who reported exposure to work-related injuries and abuse were more likely to consume alcohol and with greater frequency. Conversely, and contrary to our hypotheses, we found that workers who live in homes built from inadequate materials and those who lack of access to basic services and luxury items were less likely to consume alcohol and with less frequency.

One possible pathway that we considered to explain our findings was one where material deprivation leads to chronic psychological distress, which then leads to increased palliative alcohol consumption (as seen in Hill, 2005; Pollack et al., 2005). Another pathway could also be related to decreased access to alcohol as is explained by Grzywacz, Quandt, Isom, and Arcury (2007). For example, workers exposed to lack of access to basic services and luxury items and those who live in inadequately built homes may live in rural and unincorporated areas with less access to purchasable alcohol and be less likely to consume (Duncan, 2008). On the contrary, Mexican farmworkers that live in employee provided housing are conceivably faced with an increased burden of social isolation as a result of living away from family and social circles that provide social support, resulting in an increased likelihood to consume alcohol. Employer provided housing is ordinarily limited only to the working parties and generally excludes primary family members and forces workers to travel alone (Hovey \& Magaña, 2002; Palacios et al., 2000; PalaciosNava \& Moreno-Tetlacuilo, 2004). Previous research has shown that migrant workers, who travel without their families, face loneliness, social isolation, and decreased social support (Hovey \& Magaña, 2002; Worby \& Organista, 2007), that could exacerbate psychological distress and depressive symptoms (Grzywacz et al., 2010). Trotter II's (1985) work with farmworkers in the U.S. found that heavier drinking takes place in agricultural work sites where men have traveled without families, were geographically isolated, and lived in housing arranged through contractors, which is a very common arrangement for farmworkers in Mexico (Palacios-Nava \& Moreno-Tetlacuilo, 2004). Overcrowding, lack of mobility, lack of autonomy, and lack of privacy present in employer provided housing can also contribute to psychological distress that leads to consumption of alcohol (Hill \& Angel, 2005; Palacios-Nava \& Moreno-Tetlacuilo, 2004; Pollack et al., 2005).

Reported exposure to safety-related hazards, work organization hazards, and ergonomic hazards were all associated with consumption and frequency of consumption in our sample. Research shows that hazardous work environments can cause detrimental levels of 
psychological distress (Marchand, Demers, \& Durand, 2005; Tawatsupa et al., 2010). Workrelated stressful conditions may increase negative emotions, which in turn can manifest into increased levels of alcohol consumption (Frone, 1999; Richman, Shinsako, Rospenda, Flaherty, \& Freels, 2002). For example, participants of our study who reported exposure to work organization related hazards, which included employer-related abuse, were more likely to consume and with more frequency than workers who did not report any work organization related hazards. This is consistent with research showing that exposure to workrelated harassment/abuse is associated with increased alcohol consumption, an association believed to be mediated by the psychological burden caused by persistent work-related distress (Richman et al., 2002). Hovey and Magaña's (2002) findings show that worker discrimination, abuse, and exploitation are pervasive in agricultural work. Likewise, the work of Keyes, Hatzenbuehler, and Hasin (2011) demonstrates that general perceptions of discrimination are associated with increased alcohol consumption among racial/ethnic minorities. Consequently, minority farmworkers, particularly those of indigenous descent face a greater burden of employer and fellow employee abuse (Palacios et al., 2000; Palacios-Nava \& Moreno-Tetlacuilo, 2004). It is plausible that the combined exposure to detrimental housing conditions, social isolation, lack of autonomy, and persistent abuse have detrimental effects on the psychological well-being of farmworkers, which can lead to increased levels of consumption that are harmful to their health. Further, participants of our study who reported experience of a work related injury had higher odds of alcohol consumption. This observation is consistent with studies have shown that there is a significant relationship between problem drinking and occupational injuries (Campillo et al., 1998; Grzywacz et al., 2007; Wang et al., 2010; Webb et al., 1994; Zhou \& Roseman, 1994). Specifically, Grzywacz et al. (2007) found that while alcohol consumption rates vary among farmworkers, there are significant proportions that consume at rates that generate significant increases in their risk of injury. In addition, Stallones and Xiang (2003) found that consumption at even moderate rates can aggravate the risk of occupational injury in agricultural work.

We suggest that given the dangers of alcohol use in the agricultural labor environment, it is imperative to consider how working and living conditions affect consumption patterns of agricultural workers. Growers and agricultural labor contractors alike should consider making changes to living and working conditions that can have a positive impact on laborers' psychological distress. Small improvements to living conditions that increase access to basic services, decrease overcrowding, and improve level of comfort in employee provided living spaces should be considered. While there may be budgetary barriers for growers to improve living conditions for farmworkers during their seasonal stay, it may be important to consider the detrimental effects that alcohol consumption has on employee productivity (Goetzel, Hawkins, Ozminkowski, \& Wang, 2003) and the risk of serious injury (Grzywacz et al., 2007; Wang et al., 2010), which can increase costs to the employer. However, our findings and those present in the literature generate a need for the institutions that manage the standards for farmworker living conditions to review and enforce the housing infrastructure, along with employers, not only to diminish costs but to improve the physical, behavioral, and social wellbeing of the farmworker population.

Our findings also provide valuable knowledge to inform future preventive efforts with farmworkers. For instance, approaches that aim to decrease the impact of work related injuries with this population should consider the potential influence of alcohol consumption patterns, their association to occupational environments, and the potential cyclical nature of this relationship. While our findings do not infer causality between exposure to hazards, alcohol consumption, and work related injuries, the presence of an association between the three could suggest the need for interventions that diminish the impact of the detrimental effect of exposure to hazards. 


\section{Limitations and Strengths}

This study has several limitations. This was a secondary analysis of an established data set, which limited the exposure and outcome variables to those controlled by ENJO. Specifically, the alcohol consumption frequency variable used in the survey limited the availability to discern alcohol consumption that would be detrimental to health or beneficial to health given moderate consumption of alcohol, particularly red wine, has protective effects (Chiva-Blanch, Arranz, Lamuela-Raventos, \& Estruch, 2013; Saremi \& Arora, 2008). In addition, alcohol use was self-reported by the participants, which may have resulted in underreporting due to social desirability bias. In fact, alcohol is prohibited in most corporate farms and this could have impacted the participant's willingness to answer with honesty. These factors could have resulted in the low proportion of participants who self-reported alcohol consumption, which may have limited the statistical power to assess differences across explanatory factors, as well as potentially giving biased results. The available exposure variables also presented some limitations to this analysis. The housing adequacy score generated for this analysis was ad-hoc, and may not have adequately accounted for the differences in housing conditions. The small amount of variability present in hazard exposure, access to basic services, as well as access to luxury items, affected the statistical power to assess the impact of these variables. Despite these limitations the ENJO is one of very few farmworker population-based studies to access the health of this population. Little is known about the health of migrant farmworkers in Mexico, thus the large sample size, and population-based design are strengths of the ENJO and, in turn, this study.

\section{Conclusion}

In this study, we found preliminary evidence of an association between housing and working conditions and alcohol consumption in farmworkers. Workers, who reported living in inadequately built homes with limited access to basic services and luxury items, were less likely to consume alcohol than their counterparts that live and work in better conditions. In contrast, workers that lived in employer provided housing and had experienced work-related abuse were more likely to consume alcohol than their counterparts. Housing and working conditions of farmworkers may have important but understudied effects on the alcohol consumption and abuse trends of farmworkers. We believe that our findings warrant future exploration to examine the specific mechanisms through which housing and working conditions affect alcohol consumption outcomes of farmworkers in Mexico.

\section{References}

Arcury, T. A., Talton, J. W., Summers, P., Chen, H., Laurienti, P. J., \& Quandt, S. A. (2016). Alcohol consumption and risk for dependence among male Latino migrant farmworkers compared to Latino nonfarmworkers in North Carolina. Alcoholism: Clinical and Experimental Research, 40(2), 377-384. doi:10.1111/acer.12969

Campillo, C., Romero, M., Saldivar, G., \& Ramos, L. (1998). Problems associated with hazardous and harmful alcohol consumption in Mexico Recent Developments in Alcoholism (pp. 397-413): Springer.

Chiva-Blanch, G., Arranz, S., Lamuela-Raventos, R. M., \& Estruch, R. (2013). Effects of wine, alcohol and polyphenols on cardiovascular disease risk factors: evidences from human studies. Alcohol and alcoholism, 48(3), 270-277.

Duncan, J. (2008). Causes of Inadequate Housing in Latin America and the Caribbean: Habitat for Humanity.

Frone, M. R. (1999). Work stress and alcohol use. Alcohol research and health, 23(4), 284-291.

Goetzel, R. Z., Hawkins, K., Ozminkowski, R. J., \& Wang, S. (2003). The health and productivity cost burden of the "top 10" physical and mental health conditions affecting six large US employers in 1999. Journal of occupational and environmental medicine, 45(1), 5-14. 
Grzywacz, J. G., Quandt, S. A., Chen, H., Isom, S., Kiang, L., Vallejos, Q., \& Arcury, T. A. (2010). Depressive symptoms among Latino farmworkers across the agricultural season: Structural and situational influences. Cultural Diversity and Ethnic Minority Psychology, 16(3), 335.

Grzywacz, J. G., Quandt, S. A., Isom, S., \& Arcury, T. A. (2007). Alcohol use among immigrant Latino farmworkers in North Carolina. American journal of industrial medicine, 50(8), 617-625.

Hill, T. D., \& Angel, R. J. (2005). Neighborhood disorder, psychological distress, and heavy drinking. Social Science \& Medicine, 61(5), 965-975. doi:10.1016/j.socscimed.2004.12.027

Hovey, J. D., \& Magaña, C. G. (2002). Psychosocial predictors of anxiety among immigrant Mexican migrant farmworkers: Implications for prevention and treatment. Cultural Diversity and Ethnic Minority Psychology, 8(3), 274.

Keyes, K. M., Hatzenbuehler, M. L., \& Hasin, D. S. (2011). Stressful life experiences, alcohol consumption, and alcohol use disorders: the epidemiologic evidence for four main types of stressors. Psychopharmacology, 218(1), 1-17.

Makela, P. (1999). Alcohol-related mortality as a function of socio-economic status. Addiction, 94(6), 867-886.

Marchand, A., Demers, A., \& Durand, P. (2005). Does work really cause distress? The contribution of occupational structure and work organization to the experience of psychological distress. Social Science \& Medicine, 61(1), 1-14.

McDermott, S., \& Lee, C. V. (1990). Injury among male migrant farm workers in South Carolina. Journal of Community Health, 15(5), 297-305.

Palacios, N., Paz, R., Aguirre, M., Daltabuit, M., Mejía, J., \& Alvarez, R. (2000). Calidad de vida, ambiente y salud de los jornaleros agrícolas del estado de Sinaloa. Calidad de vida, salud y ambiente. México, DF: Colección Multidisciplina, Centro Regional de Investigaciones Multidisciplinarias, UNAM, 301-321.

Palacios-Nava, M. E., \& Moreno-Tetlacuilo, L. M. A. (2004). Diferencias en la salud de jornaleras y jornaleros agrícolas migrantes en Sinaloa, México. salud pública de méxico, 46(4), 286-293.

Pollack, C. E., Cubbin, C., Ahn, D., \& Winkleby, M. (2005). Neighbourhood deprivation and alcohol consumption: does the availability of alcohol play a role? International journal of epidemiology, 34(4), 772-780.

Richman, J. A., Shinsako, S. A., Rospenda, K. M., Flaherty, J. A., \& Freels, S. (2002). Workplace harassment/abuse and alcohol-related outcomes: the mediating role of psychological distress. Journal of studies on alcohol, 63(4), 412-419.

Saremi, A., \& Arora, R. (2008). The cardiovascular implications of alcohol and red wine. American journal of therapeutics, 15(3), 265-277.

SEDESOL. (2009). Encuesta Nacional de Jornaleros: ENJO. Mexico D.F.

Mejorando la Atención a la Poblacion Jornalera Agricola: Una Propuesta metodologica para la Intervencion Interinstitucional Focalizada, (2011).

Stallones, L., \& Xiang, H. (2003). Alcohol consumption patterns and work-related injuries among Colorado farm residents. American journal of preventive medicine, 25(1), 25-30.

StataCorp, L. (2013). Stata 13: StataCorp LP., College Station, Texas, United States. http://www/. stata. com.

Tawatsupa, B., Lim, L. L., Kjellstrom, T., Seubsman, S.-a., Sleigh, A., \& Team, T. C. S. (2010). The association between overall health, psychological distress, and occupational heat stress among a large national cohort of 40,913 Thai workers. Global health action, 3.

Trotter II, R. T. (1985). Mexican-American Experience with Alcohol The American experience with alcohol (pp. 279-296): Springer.

Wang, L., Wheeler, K., Bai, L., Stallones, L., Dong, Y., Ge, J., \& Xiang, H. (2010). Alcohol consumption and work-related injuries among farmers in Heilongjiang Province, People's Republic of China. American journal of industrial medicine, 53(8), 825-835. 
Webb, G. R., Redman, S., Hennrikus, D. J., Kelman, G. R., Gibberd, R. W., \& Sanson-Fisher, R. W. (1994). The relationships between high-risk and problem drinking and the occurrence of work injuries and related absences. Journal of studies on alcohol, 55(4), 434-446.

WHO. (2014). Global status report on alcohol and health-2014. (9240692762). World Health Organization.

Worby, P. A., \& Organista, K. C. (2007). Alcohol use and problem drinking among male Mexican and Central American Im/migrant laborers a review of the literature. Hispanic Journal of Behavioral Sciences, 29(4), 413-455.

Zhou, C., \& Roseman, J. M. (1994). Agricultural injuries among a population-based sample of farm operators in Alabama. American journal of industrial medicine, 25(3), 385-402.

Author Information

Luis Valdez, MPH

UA Collaboratory for Metabolic

Disease Prevention \& Treatment

University of Arizona

3950 S. Country Club, Suite 330

Tucson, AZ 85714

Tel: (520) 626-4745

Email: jolitrac@email.arizona.edu

* corresponding author 